\title{
Transcriptomic and lipidomic profiling of eicosanoid / docosanoid signalling in affected and non-affected skin of human atopic dermatitis patients
}

Daniel Töröcsik ${ }^{1,}$ Christin Weise ${ }^{2}$, Janine Gericke ${ }^{3}$, Andrea Szegedi ${ }^{1}$, Renata Lucas ${ }^{1}$, Johanna Mihaly ${ }^{3}$, Margitta Worm², Ralph Rühl ${ }^{3,4}$

${ }^{1}$ Department of Dermatology, Faculty of Medicine, University of Debrecen, Debrecen, Hungary

2 Allergy-Center-Charité, Department of Dermatology and Allergology, Charité Universitätsmedizin, Berlin, Germany;

${ }^{3}$ Department of Biochemistry and Molecular Biology, University of Debrecen; Hungary;

${ }^{4}$ Paprika Bioanalytics BT, Debrecen, Hungary.

This article has been accepted for publication and undergone full peer review but has not been through the copyediting, typesetting, pagination and proofreading process, which may lead to differences between this version and the Version of Record. Please cite this article as doi: 10.1111/exd.13867

This article is protected by copyright. All rights reserved. 


\section{Corresponding author:}

Dr. Ralph Rühl

Paprika Bioanalytics BT

Mezögazdász utca 62

H-4002 Debrecen

Tel: +36-302330 501

E-mail: ralphruehl@web.de

\section{Abstract}

Lipoxygenases (LOX) and cycloxygenase (COX) are the main enzymes for PUFA-metabolism to highly bio-active prostaglandins, leukotrienes, thromboxanes, lipoxines, resolvins and protectins. LOX and COX pathways are important for the regulation of pro-inflammatory or pro-resolving metabolite synthesis and metabolism for various inflammatory diseases such as atopic dermatitis (AD). In this study we determined PUFAs and PUFA-metabolites in serum as well as affected and non-affected skin samples from AD-patients and the dermal expression of various enzymes, binding proteins and receptors involved in these LOX and COX pathways. Decreased EPA and DHA levels in serum and reduced EPA level in affected and non-affected skin were found; in addition n3/n6-PUFA ratios were lower in affected and non-affected skin and serum. Mono-hydroxylated PUFA-metabolites of AA, EPA, DHA and the sum of $A A$, EPA and DHA metabolites were increased in affected and non-affected skin. COX1 and ALOX12B expression, COX and 12/15-LOX metabolites as well as various lipids, which are known to induce itch (12-HETE, LTB4, TXB2, PGE2 and PGF2) and the ratio of pro-inflammatory vs pro-resolving lipid mediators in non-affected and affected skin as well as in the serum of $A D$ patients were increased, while $n 3 / n 6$-PUFAs and metabolite ratios were lower in non-affected and affected AD-skin. Expression of COX1 and COX-metabolites were even higher in non-affected AD-skin. To conclude, 12/15-LOX and COX pathways were mainly upregulated, while n3/n6-PUFA and metabolite ratios were lower in AD-patients skin. All these parameters are a hallmark of a pro-inflammatory and non-resolving environment in affected and partly in non-affected skin of AD-patients.

This article is protected by copyright. All rights reserved. 


\section{Introduction}

Atopic dermatitis (AD) is a chronic and relapsing inflammatory skin disease, characterized by dryness, eczematous skin lesions, pruritic excoriations and lichenification ${ }^{1,2}$. In the background disturbed skin barrier, altered immune response of various immune cells, mainly lymphocytes and eosinophils, leading to a Th1 / Th2 shift, defects in permeability barrier functions and IgE mediated mechanisms all play a role ${ }^{1,2}$. Although external factors are pivotal in atopy development, studies confirming the association of $A D$ with various polymorphisms as reviewed in ${ }^{3}$, also pointed on the importance of genetic factors.

Polyunsaturated fatty acids (PUFA) and especially their bioactive metabolites the eicosanoids and docosanoids are involved in the modification of various aspects of inflammatory responses in $A D$ (reviewed in ${ }^{4,5}$ ). Arachidonic acid (AA), docosahexaenoic acid (DHA) and eicosapentaenoic acid (EPA) are the major precursors of a large variety of lipid mediators with pro-inflammatory (prostaglandins, leukotrienes, thromboxanes) or pro-resolving (lipoxins, resolvins, protectins, maresins) activity ${ }^{6}$. Cyclooxygenase (COX) and lipoxygenases (LOX) pathways and further enzymes such as prostaglandin-synthases, thromboxane synthase and leukotriene-synthases are involved in bioactive eicosanoid / docosanoid synthesis during inflammatory conditions of allergic diseases ${ }^{5,7-10}$. Various eicosanoids / docosanoids were shown to be potent activators of GPCRs, such as leukotriene B4 (LTB4) receptors (BLT1 and 2), cysteinyl-leukotriene receptors (CYSLTR 1 and 2), thromboxane receptor (TXB2), prostaglandin receptors for prostaglandin D2 (PGD2) (DP1 and 2), prostaglandin E2 (PGE2) (EP1, 2, 3 and 4), prostaglandin F2 (PGF2) (FP), lipoxin receptor (LXA4R) as well as activators of nuclear hormone receptors ${ }^{4}, 6$. Mainly the peroxisome proliferator-activated receptors (PPARa and PPARY) are activated by fatty acids and eicosanoids / docosanoids ${ }^{11,12}$. PPARa plays an important role during skin development, maturation of epidermal barrier and sebocyte activation ${ }^{13}$, 14 , while PPARY seems to be involved in sebaceous gland differentiation and immunoregulatory processes ${ }^{15-17}$. Ligand trafficking is mediated via fatty acid binding proteins (FABP), which are intracellular transporters and attractors of various fatty acids. FABP4 seems to be associated with PPARmediated signaling and FABP7 with attraction of DHA ${ }^{18,19}$.

This article is protected by copyright. All rights reserved. 
In this study we investigated eiconsanoid- / docosanoid-mediated signaling via enzyme, receptor and binding protein expression using transcriptomic as well as eicosanoid / docosanoid levels using lipidomic techniques in the skin of healthy volunteers and affected / non-affected skin of AD patients. We used and applied an optimized lipidomic method for analyzing micro-amounts of available skin biopsies. Our aim was to get an overview how eicosanoid / docosanoid signaling is altered in atopic dermatitis and based on our results to further plan targeted therapy for atopic dermatitis using selected agonists / antagonists for receptors and / or enzymatic inhibitors of various involved enzymes.

\section{Materials and methods}

\section{Sample collection}

Skin biopsy specimens were taken after obtaining informed consent in involved areas from six patients with $A D$ (two male and four female patients; average age 31 years; according to the declaration of Helsinki, and from six non-atopic healthy volunteers (two male and four female individuals; average age 30 years) characterized by the absence of personal or family history of atopic disease. In case of AD patients, one biopsy of affected skin and one biopsy of non-affected skin were taken from each patient. Specimens were immediately frozen in dry ice and stored at $-70^{\circ} \mathrm{C}$ until RNA isolation or HPLC analysis. For HPLC-MS analysis just 3 patients were included, due to limited available skin tissue (average age 28, SCRORAD 42.5, average total IgE $4126 \mathrm{KU} / \mathrm{L}$ and specific IgE $49 \mathrm{KU} / \mathrm{L}, 1$ male / 2 female, two patients are of extrinsic and one patient of combined intrinsic / extrinsic phenotype). Additionally, serum samples were drawn from the same patients and healthy controls and were kept at $70{ }^{\circ} \mathrm{C}$ until analysis. For preparation of the serum samples blood was allowed to clot for 10 minutes at room temperature and spun down at $1500 \mathrm{~g}$ and $4^{\circ} \mathrm{C}$. The serum was aliquoted to $250 \mu \mathrm{l}$ portions and stored at $-80^{\circ} \mathrm{C}$ until further analysis. Ethical approval for the study was obtained from the local ethics committee of the University of Debrecen in Hungary (EA1/168/06).

This article is protected by copyright. All rights reserved. 


\section{Analysis of mRNA expression}

Skin samples were homogenized with QIAGEN Tissue Lyser in Tri reagent solution (Molecular Research Center Inc., Cincinnati, OH, USA) using previously autoclaved QIAGEN metal beads and total RNA was isolated according to the manufacturer's guidelines. The concentration and purity of RNA were measured by means of NanoDrop spectrophotometer (Thermo Scientific, Bioscience, Budapest, H). RNA quality was checked using agarose gelelectrophoresis. For real-time quantitative PCR (QRT-PCR) total RNA was reverse transcribed into cDNA using the SuperScript II First Standard Synthesis System (Invitrogen, Life Technologies Magyarország Kft., Budapest, H). QRT-PCR was carried out in triplicates using pre-designed MGB assays ordered from Applied Biosystems (Applied Biosystems, Applera, Budapest, $H$ ) using an ABI Prism 7900. Relative mRNA levels were calculated with either the comparative CT or standard curve methods normalized to cyclophilin A mRNA. Sequence Detector Software (version 2.1) (Applied Biosystems) was utilized for data analysis, and relative fold induction was determined by the comparative threshold cycle method.

\section{Immunohistochemistry}

The tissue cryo-sections ( $5 \mu \mathrm{m}$ ) were incubated with antibodies against the human ALOX12B (Abgent, Oxfordshire, UK) or COX1 (5F6/F4, Abcam plc, Cambridge, UK), followed by biotinylated goat anti-rabbit IgG and anti-mouse IgG, respectively (both DAKO Diagnostika, Hamburg, D). Nonspecific binding was blocked with $5 \%$ bovine serum albumin (BSA) in PBS for $30 \mathrm{~min}$ at room temperature. Negative controls were performed by omitting the primary antibody. Detection was performed using Dako REAL ${ }^{\mathrm{TM}}$ Detection System Alkaline Phosphatase/RED (DAKO) and by hematoxylin counterstaining (Merck, Darmstadt, D). Finally, images were taken at x100 magnification using the Axioplan light microscope equipped with a AxioCamHR and Axiovision analysis software (Carl Zeiss, Jena, D).

This article is protected by copyright. All rights reserved. 


\section{HPLC-ESI-MS-MS analysis of free fatty acids and eicosanoids and docosanoids in skin and serum}

The previously described procedure for the HPLC-ESI-MS-MS method was followed with minor modifications ${ }^{7,20,21}$.

Sample preparation. The whole analytical sample preparation procedure is based on an established method used for retinoid quantification ${ }^{22}$. In summary, to $50 \mu$ of serum or 50 $\mathrm{mg}$ of a skin biopsy (if less that $50 \mathrm{mg}$ of skin biopsy was present, water was added to yield $50 \mathrm{mg}$ of sample weight for our standardized extraction protocol), $150 \mu$ acetonitrile was added and the skin samples were cut with scissors in small pieces on ice. These mixtures were shaken for $3 \mathrm{~min}$, the precipitated protein was centrifuged at $13.000 \mathrm{rpm}, 4^{\circ} \mathrm{C}$ for 6 min, $130 \mu \mathrm{L}$ of the resulting supernatant was spiked with $10 \mu \mathrm{l}$ isotope supernatant mix containing (prostaglandin D2 (PGD2) (D4), 5-hydroxy-eicosatetraenoic acid (5-HETE) (D8), 15-hydroxy-eicosatetraenoic acid (15-HETE) (D8) and 9-hydroxy-octadecadienoic acid (9HODE) (D4), each at a concentration of $10 \mu \mathrm{g} / \mathrm{ml}$ as the internal control), evaporated in Eppendorf reaction vials with an Eppendorf concentrator at $30^{\circ} \mathrm{C}$ for 60 min until the sample volume was $~ 10 \mu \mathrm{l}$. The Eppendorf concentrator was vented with highly pure argon to prevent degradation of eicosanoids and docosanoids. The semi-dried extract was resuspended with approximately $25 \mu \mathrm{l}$ of HPLC solvent A [64.3\% water (water, Chromasolv Plus from Sigma-Aldrich, $\mathrm{H}$ ) and $35.5 \%$ acetonitrile (Merck KGaA, D) and $0.2 \%$ formic acid (Fluka, H)] to yield exactly $35 \mu \mathrm{l}$, then vortexed (15 sec), shaken (3 min) and transferred into micro-injection inserts vials (Waters, H). These glass vials with the $35 \mu$ l extract were transferred into brown screw top vials with PTFE / silicone septa sample (Waters, H) and placed in the pre-cooled $\left(15^{\circ} \mathrm{C}\right)$ autosampler of the Waters $2695 \mathrm{XE}$ separation module and immediately analysed.

Chromatographic system. The HPLC system consisted of a Waters 2695XE separation module (Waters, $\mathrm{H}$ ) including a gradient pump, autosampler, degasser and a heated column compartment. A MS-MS detector with an ESI ionizing option was used (Micromass Quattro Ultima PT from Waters, UK) as a detector. The system was controlled via the MassLynx software (Waters, $\mathrm{H}$ ).

This article is protected by copyright. All rights reserved. 
HPLC conditions. The eluents were degassed in the Waters 2695XE separation module prior to mixing, then passed through an in-line filter (1-2 $\mu \mathrm{m}$; Knauer, $\mathrm{D})$ before reaching the analytical column (LiChroCART, $125 \times 2$ mm; Superspher 100, RP-18, endcapped) from Merck KgaA (D) embedded in the column compartment. A multilinear gradient was formed from solvent $A$ (see above) and solvent $B$ (methanol; Merck KGaA D). The gradient consisted of the following steps: $0.0 \mathrm{~min} 20 \% \mathrm{~B}, 3.0 \mathrm{~min} 20 \% \mathrm{~B}, 5.0 \mathrm{~min} 60 \% \mathrm{~B}, 15.0 \mathrm{~min}$ $100 \% \mathrm{~B}, 15.9 \mathrm{~min} 100 \% \mathrm{~B}$ and $16.0 \mathrm{~min} 5 \% \mathrm{~B}$. The flow rate was adjusted to $0.4 \mathrm{ml} / \mathrm{min}$ and the column was heated to $40^{\circ} \mathrm{C}$. From the same biological extract, $11 \mu \mathrm{l}$ for each HPLC analysis was used. This step was performed twice using the same HPLC conditions and two different MS-MS analysis options (method A or B) for optimized resolution and quantification of a larger variety of analytes.

MS options. The Micromass Quattro Ultima PT was controlled via the MassLynx software. Argon with an inlet pressure of 0.8 bar was used. ESI (electro spray ionization source, Waters, $\mathrm{H}$ ) was vented by nitrogen continuously produced by the nitrogen generator (Peak Scientific NM30 Nitrogen generator) including compressor (Waters, $H$ ) with the inlet flow set at 3.6 e-3 mbar.

Multiple reaction monitoring settings: ESI, with a negative ESI - setting, was performed with the HPLC eluent following the ion source temperature of $85^{\circ} \mathrm{C}$. The desolvation gas flow was $780 \mathrm{l} / \mathrm{h}$, the desolvation temperature was $400^{\circ} \mathrm{C}$, the cone gas flow was $10 \mathrm{l} / \mathrm{h}$, the capillary current was $3 \mu \mathrm{A}$, and the cone voltage was $50 \mathrm{~V}$. Aperture voltage was set at $0 \mathrm{~V}$ and the $\mathrm{RF}$ lens voltage was set at $35 \mathrm{~V}$ (for 1 ) and $0.2 \mathrm{~V}$ (for 2 ). The analyzer settings were LM1 resolution 14.5; HM1 resolution 14.5; Ion energy 1 0.7; entrance -1 ; collision 0 (collision parameters are set for each substance at the MS - method parameters); exit 2; LM2 resolution 14.5; HM2 resolution 14.5; Ion energy 25.0 and a multiplier energy of $650 \mathrm{~V}$.

Multiple reaction monitoring settings for PUFA, eicosanoids/docosanoids quantification, retention times, collision energy, used method, time segments, correlation coefficient, individual recoveries as well as inter-day and intra-day -variations are listed in supplementary table 1.

This article is protected by copyright. All rights reserved. 
Standard solutions. Stock solutions of the PUFAs, eicosanoids and docosanoids were prepared by dissolving the solutions obtained from Cayman-Chemicals (Tallin, EST), BioMol International (Kastel-Med KFT, Budapest, H), Sigma-Aldrich (Budapest, H), Larodan Lipids (Malmö, S) and Dr. Charles Serhan (Harvard University, MD, USA) with methanol to yield a final concentration of $10 \mu \mathrm{g} / \mathrm{ml}$. All stock solutions were stored in darkness at $-80^{\circ} \mathrm{C}$. The reference PUFAs, eicosanoids and docosanoids were used for the assay validation.

Quantification. Individual eicosanoids and docosanoids were quantified based on the determination of the "Area Under the Curve" (AUC) and compared with the AUC of standard compounds. To ensure optimal extraction and precision for quantification isotope labelled standard compounds were used (PGD2 (D4), 5-HETE (D8), 15-HETE (D8) and 9-HODE (D4)) and retention times and extraction efficiency based on an average of all four added isotopes was calculated and adjusted. This analytical procedure was established for liquids and tissue analysis.

\section{Statistics}

LC-MS data are shown as mean of three individual measurements and standard error mean values per data point. Values which were determined under the quantification limit $(0.2$ $\mathrm{ng} / \mathrm{ml}$ (or $\mathrm{g})$ ) were replaced with a value of half of the detection limit $(0.1 \mathrm{ng} / \mathrm{ml}$ (or $\mathrm{g})$ ) for further calculation of statistics as well as ratios and sums. For PCR data each data points stands for 6 subjects. Statistical analysis was performed using the program SPSS 16.0 (SPSS Inc., Chicago, IL, USA). A P value of $<0.05$ was considered to be significant using student $\mathrm{t}$ test for independent samples.

\section{Results}

Increased AA levels in affected and non-affected skin of AD-patients and reduced n3/n6-PUFA ratios in skin of AD-patients: Initially, we examined the levels of free PUFAs in skin from healthy as well as affected and non-affected skin of AD-patients. AA levels were increased in non-affected (2.0-fold) and affected skin (1.8-fold) of AD-patients, 
while no alteration was observed in AD-patients serum. EPA levels in skin and serum were comparable and serum levels of DHA were lower in AD-patients serum (Table 1 and 2, Figure 1). Ratios of $n 3 / n 6-P U F A$ such as EPA/AA and DHA/AA were also lower in nonaffected and affected skin as well as in serum of AD-patients (Figure 2).

Increased levels of PUFA-hydroxy-metabolites in the AD-patients skin: Focusing on hydroxy-metabolites from PUFAs, we found that the levels of AA-hydroxy-metabolites, the hydroxy-eicosatetraenoic acids (HETEs), were increased in non-affected (2.5-fold) and affected skin (4.5-fold) of AD-patients as well as increased in AD-serum (2-fold). Hydroxymetabolites of EPA, the hydroxy-eicosapentaenoic acids (HEPEs), were just increased in the affected skin (1.6-fold) of AD-patients and comparable in AD-patients serum. Hydroxymetabolites of DHA, the hydroxy-docosahexaenoic acids (HDHAs), were increased in nonaffected (1.8-fold) and affected skin (6.5-fold) of AD-patients, while they were decreased (0.3-fold) in AD-serum.

The ratios of HEPEs/HETEs were reduced in both non-affected and affected skin of ADpatients and slightly decreased in AD-patients serum. Ratios of HDHAs/HETEs were also reduced in non-affected $A D$-patients skin and remained unchanged in affected skin and decreased in serum of AD-patients (Figure 2).

Increased concentrations of PUFA-metabolites in the skin of AD-patients: Next, we focussed on the sum of AA-metabolites (AA-met) as well as DHA-metabolites (DHA-met) which were both increased in non-affected (AA-met: 3.1-fold; DHA-met: 1.8-fold) and affected skin (AA-met: 2.9-fold; DHA-met: 4.0-fold) of AD-patients, while just for the AAmetabolites the serum levels were increased (1.7-fold) and DHA-metabolites were even decreased (0.3-fold). EPA-metabolites (EPA-met) remained comparable in AD-patients serum and were increased (2.2-fold) in affected skin of AD-patients.

To further evaluate the ratios between the PUFAs, we calculated ratios of EPA-, DHA- and AA-metabolites. The ratios of AA-metabolites/AA, EPA-metabolites/EPA and DHAmetabolites/DHA were increased in affected skin, while AA-metabolites/AA and DHAThis article is protected by copyright. All rights reserved. 
metabolites/DHA were just increased in non-affected skin of AD-patients (Figure 2). Serum levels were just increased for AA-metabolites/AA, EPA-metabolites/EPA, while DHAmetabolites/DHA were even decreased. Ratios of EPA-metabolites/AA-metabolites and DHAmetabolites/AA-metabolites were reduced in non-affected skin of AD-patients, while DHAmetabolites/AA-metabolites even increased in affected skin of AD-patients. The serum ratios of EPA-metabolites/AA-metabolites remained unchanged and DHA-metabolites/AAmetabolites were lower (Figure 2).

\section{Increased levels of 5-lipoxygenase-derived metabolites in affected skin of AD-} patients: When focussing on the synthesis pathways, we first evaluated 5-lipoxygenase metabolism (ALOX5, 5-LOX), which is the key enzyme in the synthesis of mainly proinflammatory leukotrienes. The expression of ALOX5 was not altered in AD-patients skin, while 5LOX-activating protein (FLAP) and leukotriene hydroxylase (LTA4H) were less expressed in affected skin (FLAP: 0.3-fold; LTA4H: 0.4-fold) of AD-patients (Figure 3,

Supplementary Table 2). The expression of leukotriene receptors BLT1 was strongly increased in non-affected skin (2.1-fold) while CYSTL2 was reduced in non-affected (0.1fold) and affected (0.2-fold) skin of AD-patients skin.

Surprisingly, the sum of the 5-LOX metabolites and LTB4 was just significantly increased in affected skin of $A D$-patients vs healthy or non-affected skin and even significantly decreased in AD-patients serum (Figure 2 and Table 2).

\section{8-Hydroxylation-pathway metabolites increased in affected and non-affected} skin of AD-patients: Next, we calculated the sum of 8-hydroxylation-pathway metabolites which were just significantly increased in affected skin (3.1-fold) of AD-patients, while serum and affected skin levels remained non-significantly altered (Figure 2).

Increased 12/15-LOX pathways in skin and serum of AD-patients: To assess the dermal expression profiles of the 12/15-lipoxygenases we focussed on ALOX12B (arachidonate lipoxygenase 12B) and ALOXE3 (arachidonate lipoxygenase 3), which were both significantly increased in non-affected (ALOX12B: 2.5-fold; ALOXE3: 2.4-fold) and 
affected AD-skin (ALOX12B: 3.7-fold; ALOXE3: 3.0-fold) in comparison to healthy skin (Figure 3, Supplementary Table 2).

The enhanced ALOX12B gene expression in skin of AD-patients was further verified at the protein levels using immunohistochemical stainings (Figure 4). In the skin of AD-patients hyperplasia and thickening of epidermis was evident and cell infiltration was prominent in comparison to the healthy control. Thereby, the histological features of atopic dermatitis are more distinctive in affected than in non-affected skin. The documented dermal infiltration is characterized by a perivascular pattern in non-affected skin, whereas affected AD skin possesses a rather diffuse distribution of infiltrating cells.

$A D$ skin featured a remarkably higher ALOX12B protein expression compared to healthy skin (Figure 4), with strong staining intensities in keratinocytes (marked by the black arrow) and in dermal infiltrating cells (marked by the green arrow). The increased epidermal thickness and degree of infiltration in affected vs. non-affected skin was associated with a higher ALOX12B protein expression.

Skin levels originating from 12-LOX metabolism displayed a tendency to increase in nonaffected (2.6-fold) and affected skin (2.1-fold) of AD-patients, while the sum of 15-LOX metabolites was significantly increased both in non-affected (1.6-fold) and affected skin (6.1-fold) of AD-patients.

\section{Upregulated cyclooxygenases (COX)-mediated signaling pathway in AD-patients:} Cyclooxygenases are the major enzymes for prostaglandin synthesis. The expression of COX1 was increased both in non-affected skin (9.4-fold) as well as affected skin (6.0-fold) of AD-patients (Figure 2). Expression of prostaglandin E synthase (PGES) was strongly decreased in non-affected skin $(<0.01$-fold) of AD-patients, while it was increased in affected skin (3.6-fold) of AD-patients (Figure 3, Supplementary Table 2).

This article is protected by copyright. All rights reserved. 
To confirm the increased COX1 gene expression also at the level of protein synthesis we performed immunohistochemistry using whole skin samples (Figure 4). COX1 was broadly distributed throughout the $A D$ lesions, which due to the epidermal thickening of $A D$ skin, resulted in a remarkably higher COX1 protein expression in the epidermis (marked by the black arrows) than observed in healthy skin. Lesional skin of AD-patients is characterized by a massive infiltration of inflammatory cells involved in disease pathology (reviewed in ${ }^{2}$ ). A proportion of infiltrating cells expressed COX1 thereby augmenting the COX1 protein amount in $A D$ lesions (marked by the green arrow). Interestingly, the percentage of COX1 expressing infiltrating cells seems to be higher in affected than in non-affected skin.

In agreement with the expression and protein levels the sum of COX-metabolites was significantly increased in non-affected (3.6-fold) and in affected skin (2.1-fold) of ADpatients.

Pro-inflammatory vs pro-resolving lipid mediators. For further evaluation, we formed and calculated functional clusters of eicosanoids / docosanoids according their biological mediated activities. Firstly, we summarised the sum of pro-inflammatory mediators (LTB4, leukotriene C4 (LTC4), PGD2, PGE2, PGF2, 15-deoxy- $\Delta 12$,14-prostaglandin D2 (d15d12PGD2), thromboxane B2 (TXB2) and 5-oxo-eicosatetraenoic acid (5-KETE)) as displayed in Figure $2 \mathrm{~A}$ and calculated a ratio versus the sum of pro-resolving lipid mediators (lipoxin A4 (LXA4), lipoxin B4 (LXB4), resolvin D1 (RvD1), resolvin D2 (RvD2), protectin D1 (PD1), maresin (MAR)). This ratio was increased in non-affected skin (1.5-fold) and even stronger in affected skin (2.3-fold) of AD-patients as well as a strong increase (4.8-fold) was observed in serum of AD-patients vs. healthy volunteers (Figure $2 A$ ).

\section{Reduced expression of peroxisome proliferator-activated receptors (PPAR) and PPAR-target gene expression:}

The expression of PPARa and $y$ was significantly decreased in the affected skin (PPARa: 0.5fold; PPAR $\mathrm{:}$ 0.2-fold) of AD-patients. While the expression of PPAR-target genes like RETSAT and CD36 displayed a tendency of reduced expression in affected skin, the This article is protected by copyright. All rights reserved. 
expression of fatty acid binding proteins (FABPs) was not altered, just a tendency of reduced expression was observed in the affected skin of AD-patients (Figure 3, Supplementary Table 2). To assess the presence of possible PPAR activators, we calculated the sum of PPARligands, such as d15d12PGJ2, prostaglandin J2 (PGJ2), PGD2, 5-KETE, 12-oxoeicosatetraenoic acid (12-KETE), 15-oxo-eicosatetraenoic acid (15-KETE), 13-oxo-9,11octadecadienoic acid (13-KODE) and 4-hydroxy-docosahexaenoic acid (4-HDHA). We calculated a tendency of increased levels in affected skin found for PGD2, 12-KETE, 15-KETE and 13-KODE, while for PGJ2 and even 4-HDHA a significant increase was found in affected skin of AD-patients (Table 2). Sums of these ligands were just significantly higher in affected skin vs healthy skin (2.6-fold) (Figure 2E).

The expression of the peroxisome proliferator-activated receptors (PPARs) was significantly decreased for PPARa and $y$ in affected skin (PPARa: 0.5-fold; PPAR $y$ : 0.2-fold) of ADpatients. The expression of fatty acid binding proteins (FABPs) was not altered, just a tendency of reduced expression was observed in affected skin of AD-patients. Other PPARtarget genes such as RETSAT and CD36, besides FABP4, displayed also a tendency of reduced expression in affected skin (Figure 3, Supplementary Table 2).

\section{Discussion:}

Atopic dermatitis is a chronic inflammatory skin disease with a prominent involvement of eicosanoids / docosanoids ${ }^{7,8}, 23-27$. In this study we made a comprehensive screening of these eicosanoids and docosanoids as well as expression of eicosanoid/docosanoid metabolizing enzymes, binding proteins and receptors in affected and non-affected skin of AD-patients compared to skin of healthy volunteers. We observed; a) Strong increase of various eicosanoids and docosanoids from COX and 5-, 12- and 15-LOX and 8-hydroxylation pathways in affected and surprisingly partly also in non-affected AD-skin. b) Increased levels of n6-PUFA-derived major itch-mediators such as LTB4, TXB2, 12-HETE, PGE2 and PGF2, which are partly even higher in non-affected skin of AD-patients. c) An additional feature was the reduced $n 3 / n 6-P U F A$ as well as various $n 3 / n 6-P U F A$ metabolite ratios in affected and non-affected skin of AD-patients. d) Strongly increased itch-mediators and proinflammatory pathways in non-affected skin of AD-patients. e) Reduced PPAR-mediated

This article is protected by copyright. All rights reserved. 
signaling despite the presence of increased PPAR-ligands in affected skin of AD-patients and f) affected skin specific increased LTB4 levels. These results altogether confirm and support a chronic inflammatory condition in atopic dermatitis.

Previous studies by our groups determined strong reduced retinoid mediated signaling in skin of AD-patients ${ }^{28}$. It was also observed in this previous study, that selected receptors and enzymes were strongly upregulated even in the non-affected skin of AD patients ${ }^{28}$. Increased inflammatory signaling by reduced or increased retinoid receptor mediatedpathway signaling in the skin is of high importance and influx of inflammatory cells such as leukocytes, macrophages and lymphocytes thereby result in increased eicosanoid/docosanoid mediated signaling due to high expression of various eicosanoid/docosanoid metabolizing enzymes, binding proteins and receptors in these inflammatory cells ${ }^{29-35}$. Influx of inflammatory cells in affected and non-affected skin areas are also the major triggers for initiation and maintenance of the chronic inflammation present in $A D{ }^{10}$ and reviewed in ${ }^{2,36}$.

Surprisingly, expression of pro-inflammatory eicosanoid/docosanoid synthesis enzymes ALOX12B and COX1 were strongly increased in non-affected skin of AD-patients. Major itchmediators TXB2, LTB4, 12-HETE, PGE2 and PGF2 as well as the major itch-receptor BLT1 ${ }^{10}$, ${ }^{37-41}$ were highly present and expressed in affected and even higher expressed and present in non-affected skin of $A D$-patients, supporting the clinical findings that in $A D$ patients itching is a general feature and not a part of local inflammation. Our results also revealed that even in the non-affected skin an inflammatory background is present as indicated by upregulated levels of various eicosanoids and docosanoids and involved synthetic pathways as well as influxed inflammatory cells. In the non-affected skin, no skin specific ADphenotype could be observed because most likely this skin specific AD-phenotype is characterized by additional presence of strong pro-inflammatory lipid mediators especially originating from the 5-LOX pathway such as LTB4 (Table 2). The increased COX1 and BLT1 expression also confirmed an increased presence of inflammatory cells even in non-affected skin $4,5,8,10$. COX1 and ALOX12 were mainly present in keratinocytes in the skin and in influxed inflammatory cells (Figure $4,42,43$ ).

This article is protected by copyright. All rights reserved. 
PUFA-deficient diet is known to induce AD-like effects in mice ${ }^{44-46}$, while in AD-patients and allergen sensitized mice various PUFAs are reduced in affected skin ${ }^{47,48}$. In our study n3/n6PUFA, several n3/n6-PUFA metabolite ratios and EPA-metabolite/AA-metabolite ratios were decreased in non-affected skin of AD-patients resulting in no resolvation of the current inflammatory status and even in a more vulnerable skin towards further inflammation. Linoleic acid deficiency was described to be of relevance in AD-patients ${ }^{47}, 48$, here we further determined reduced percentile LA-metabolite ratios in non-affected skin of AD-patients (Figure 2B). We conclude that in AD-patients even a healthy looking skin is prone to a proinflammatory status and pro-itch conditions $44,45,49$. This general dysregulation of skin eicosanoid/docosanoid levels in non-affected skin, comparable to retinoid dysregulation in skin of $A D$-patients ${ }^{28}$, indicates a general and systemic background of $A D 7,28,35$. Itchinduced scratch response further results in epidermal barrier defects, bacterial infection and further inflammation of the skin mainly mediated via 5-LOX and leukotriene mediated pathways ${ }^{8,10}$. It seems that this altered itch/scratch signaling in non-affected skin, which is highly likely induced via a systemic disorder ${ }^{35,50}$, is of crucial importance for the progress and initiation of $A D$. These novel results are of high importance for prevention strategies against itch in this skin disease.

In affected skin of AD-patients even a higher increase of pro-inflammatory eicosanoids ${ }^{51}$, increased pro-inflammatory enzyme pathways and all calculated sums of LOX and COX was observed and a strong inflammatory background towards maintenance of chronic inflammatory conditions was present in $A D$. Compared to non-affected skin and even stronger in the affected skin the n3/n6-PUFA and several n3/n6-PUFA metabolite ratios were lower, while an increased ratio of pro-inflammatory vs. pro-resolving lipid mediators result in maintenance of this chronic inflammation and displaying no tendency of resolving and healing of these inflammatory conditions $45,47,48,50,52$. Reduced levels of pro-resolving derivatives (LXA4 ${ }^{53} /$ MAR $^{54}$ ) and strong increased ratio of pro-inflammatory vs. proresolving lipid mediators (Figure $2 \mathrm{~A}$ ) were also found in serum confirming this proinflammatory and non-pro-resolving environment present in AD-patients (Table 1).

A reduced expression of the leukotriene receptors (BLT1 and CYSLTR2), mainly transmitting pro-inflammatory signaling, was present in affected skin, which might indicate feedback mechanism ${ }^{10}$. Pro-resolving activity was suggested to be mediated by 15 -LOX signaling This article is protected by copyright. All rights reserved. 
resulting in the formation of pro-resolving lipid mediators ${ }^{55-58}$. Indeed in non-affected skin and affected skin of AD-patients, especially in affected skin, the 15-LOX metabolites were increased but not resulting in increased levels of pro-resolving metabolites such as LXA4, RvE- and RvD-derivatives in the skin. A tendency for increased 15-HETE was confirmed in our study in affected skin (Table 2). This reduced 12-LOX/15LOX ratio indicates a biological feedback against these pro-inflammatory conditions in skin of AD-patients ${ }^{55,56}$.

The biological meaning of increased 12-LOX pathways found in our study remains controversial. Various forms of 12/15-LOX are known and expressed in the skin with relevance for skin homeostasis and inflammatory response, reviewed in ${ }^{42}$. 12/15-LOX expression is induced by either IFNy $\left(15-\right.$-LOX2, ${ }^{59}$ ) or IL4 $\left(12 / 15\right.$-LOX, ${ }^{60}$ ) mediated pathways and 12/15-LOX deficiency results in protection against allergic airway inflammation 55, 56. Recently, ALOX12B expression was even associated with retinoid signaling ${ }^{61}$. 12-HETE, the major metabolite originating from $A A$, and further 12-LOX metabolites are transmitting pain and itch response ${ }^{62,63}$. 12-HETE is a ligand of PPARס ${ }^{64}$, a nuclear hormone receptor, which can transmit pro-inflammatory and hyperproliferative signaling present in atopic dermatitis and psoriasis ${ }^{65-67}$. On the other hand, the ALOX12 and ALOX3 metabolites, hepoxilins and trioxilins, were shown to be potent PPARa agonists and important for barrier formation (reviewed in ${ }^{42,68}$ ).

A second eicosanoid with a pivotal role is PGD2 ${ }^{4}$. It is described to induce pro-inflammatory response ${ }^{69-71}$, but partly also acts as a pro-resolving derivative ${ }^{72-74}$. PGD2 can initiate signaling via DP1 and DP2 mediated pathways, which may partly explain this pivotal role ${ }^{4}$ 75. While DP1 mainly mediates chemotaxis and pro-inflammatory signaling, DP2 induces inhibitory activity on inflammatory cell signaling and thereby mainly anti-inflammatory signaling, reviewed in ${ }^{75}$. A new concept suggests that pro-inflammatory ligands may also induce a following induction of later pro-resolving activities and PGD2 as a major driver (reviewed in ${ }^{4}$ ). Additionally PGD2 is also known to be a potent endogenous ligand of PPAR $Y$ 11,76 .

This article is protected by copyright. All rights reserved. 
PPARa/ $/$-mediated signaling has been associated with anti-inflammatory signaling (reviewed in ${ }^{16,77,78}$ ). FABPs attracts ligands like n3-PUFAs and promote PPAR-mediated signaling ${ }^{18,19}$ just as various eicosanoid-derived ligands ${ }^{11,12}$. In our study in affected skin, the sum of the potent endogenous PPAR-agonists d15d12PGJ2, 12-KETE, 15-KETE, 13-KODE, PGD2, PGJ2 and 4-HDHA ${ }^{11,17,76,79,80}$ displayed tendencies or even significant increased levels in affected skin of AD-patients. The calculated sum of the concentrations of PPAR-ligands was increased in affected skin of AD-patients suggesting an anti-inflammatory feedback mechanism. Levels of PGD2, 15-KETE and 13-KODE found in affected skin of AD-patients were even sufficient for PPAR-activation. In opposite, reduced PPAR-expression was observed in affected skin of AD-patients, indicating a reduced ability to dampen inflammation and skin healing ${ }^{13,14}$, while in the non-affected skin the increased PPARY-expression indicated an enabled antiinflammatory feedback. In summary, we observed increased calculated sums and sufficient concentration of PPAR-ligands for PPAR-mediated transactivation in affected skin, but reduced expression of PPARa and $\mathrm{y}$ as well as PPAR-target gene expression levels, resulting in reduced PPAR-mediated signaling characterizing chronic inflammatory conditions present in affected skin of $A D$-patients.

The major question is how a preventive and/or therapeutic strategy for atopic dermatitis with various approaches focusing on general strong anti-inflammatory treatments. Unfortunately eicosanoid-metabolism is mediated via the same cascade of enzymes for various PUFAs resulting in pro-inflammatory and pro-resolving metabolites 4, 6, 7, 52. Blocking one pathway may induce desired as well as detrimental effects. In addition mainly single compounds targeting one pathway are administered in current therapies. We suggest that a multiple compound treatment strategy at distinct time points during allergic response may be more beneficial. For a therapeutic approach, we specifically suggest a blocking of selective prostaglandin receptors with selective antagonists plus topical co-application of bioactive n3-originating precursors like HEPEs and HDHAs for pro-resolving lipid-mediators like resolvins, lipoxins, protectins and maresins. Unfortunately, the majorities of these suggested endogenous occurring lipid-mediators are extremely labile compounds and are not suitable for systemic and / or topical nutritional as well as pharmaceutical applications. In addition, our novel knowledge about the increased itch-markers in non-affected skin, points towards a systemic approach partly demonstrated by supplementation studies with DHA-enriched fish oil in AD-patients ${ }^{81}$ as well as targeted anti-itch preventive topical 
approach to non-affected skin areas. Currently, based on these knowledge, our group develops various approaches which can also be tested under clinical conditions.

In summary, keeping in mind the limits from the low number of examined samples, a strongly decreased n3/n6-PUFAs, n3/n6-PUFA metabolite ratios, increased ratio of proinflammatory vs. pro-resolving lipid mediators and strongly increased itch-mediators and increased pro-inflammatory cascade are hallmarks of a chronic inflammation present in the affected, but partly also in non-affected skin, of human AD-patients. The affected skin of AD-patients is indicated in comparison to the non-affected skin by additional an increased 5LOX pathway and especially LTB4 levels.

\section{Acknowledgement:}

This project was funded by the Hungarian National Research Development and Innovation Funds K109362 (RR), K128250 (ASZ) and NN117020 (DT) and also by the GINOP-2.3.2-152016-00005 and GINOP-2.3.2-15-2016-00050 grants. DT is a recipient of the János Bolyai research scholarship of the Hungarian Academy of Sciences and was also supported by the UNKP-18-4 New National Excellence Program of the Ministry of Human Capacities. CW performed the immunohistochemistry, JG, RL and JM - performed the PCR analysis, MW coordinated the clinical research and organized the skin biopsies, ASZ - helped in data interpretation, DT - partly wrote the manuscript and helped in data analysis and interpretation, RR - planed and coordinated the study, analyzed the samples using LC-MS and wrote the manuscript. The authors declare no conflict of interest.

This article is protected by copyright. All rights reserved. 


\section{References:}

1. Proksch E, Jensen JM, Elias PM. Skin lipids and epidermal differentiation in atopic dermatitis. Clin Dermatol 2003; 21:134-44.

2. Leung DY, Boguniewicz M, Howell MD, Nomura I, Hamid QA. New insights into atopic dermatitis. J Clin Invest 2004; 113:651-7.

3. Cork MJ, Danby SG, Vasilopoulos Y, Hadgraft J, Lane ME, Moustafa M, et al. Epidermal barrier dysfunction in atopic dermatitis. J Invest Dermatol 2009; 129:1892-908.

4. Buckley CD, Gilroy DW, Serhan CN. Proresolving lipid mediators and mechanisms in the resolution of acute inflammation. Immunity 2004; 40:315-27.

5. Boyce JA. Mast cells and eicosanoid mediators: a system of reciprocal paracrine and autocrine regulation. Immunol Rev 2007; 217:168-85.

6. Buczynski MW, Dumlao DS, Dennis EA. Thematic Review Series: Proteomics. An integrated omics analysis of eicosanoid biology. J Lipid Res 2009; 50:1015-38.

7. Mihaly J, Gericke J, Torocsik D, Gaspar K, Szegedi A, RühI R. Reduced lipoxygenase and cyclooxygenase mediated signaling in PBMC of atopic dermatitis patients. Prostaglandins Other Lipid Mediat 2013; 107:35-42.

8. Sadik CD, Sezin T, Kim ND. Leukotrienes orchestrating allergic skin inflammation. Exp Dermatol 2013; 22:705-9.

9. Nicolaou A. Eicosanoids in skin inflammation. Prostaglandins Leukot Essent Fatty Acids 2013; 88:131-8.

10. Oyoshi MK, He R, Li Y, Mondal S, Yoon J, Afshar R, et al. Leukotriene B4-driven neutrophil recruitment to the skin is essential for allergic skin inflammation. Immunity 2012; 37:747-58.

11. Forman BM, Chen J, Evans RM. Hypolipidemic drugs, polyunsaturated fatty acids, and eicosanoids are ligands for peroxisome proliferator-activated receptors alpha and delta. Proc Natl Acad Sci U S A 1997; 94:4312-7.

This article is protected by copyright. All rights reserved. 
12. Kliewer SA, Lenhard JM, Willson TM, Patel I, Morris DC, Lehmann JM. A prostaglandin J2 metabolite binds peroxisome proliferator-activated receptor gamma and promotes adipocyte differentiation. Cell 1995; 83:813-9.

13. Staumont-Salle D, Abboud G, Brenuchon C, Kanda A, Roumier T, Lavogiez C, et al. Peroxisome proliferator-activated receptor alpha regulates skin inflammation and humoral response in atopic dermatitis. J Allergy Clin Immunol 2008; 121:962-8 e6.

14. Michalik L, Desvergne B, Tan NS, Basu-Modak S, Escher P, Rieusset J, et al. Impaired skin wound healing in peroxisome proliferator-activated receptor (PPAR)alpha and PPARbeta mutant mice. J Cell Biol 2001; 154:799-814.

15. Schmuth M, Schoonjans K, Yu QC, Fluhr JW, Crumrine D, Hachem JP, et al. Role of peroxisome proliferator-activated receptor alpha in epidermal development in utero. J Invest Dermatol 2002; 119:1298-303.

16. Schmuth M, Moosbrugger-Martinz V, Blunder S, Dubrac S. Role of PPAR, LXR, and PXR in epidermal homeostasis and inflammation. Biochim Biophys Acta 2014; 1841:463-73.

17. Dozsa A, Dezso B, Toth BI, Bacsi A, Poliska S, Camera E, et al. PPARgamma-mediated and arachidonic acid-dependent signaling is involved in differentiation and lipid production of human sebocytes. J Invest Dermatol 2013; 134:910-20.

18. Xu LZ, Sanchez R, Sali A, Heintz N. Ligand specificity of brain lipid-binding protein. J Biol Chem 1996; 271:24711-9.

19. Tan NS, Shaw NS, Vinckenbosch N, Liu P, Yasmin R, Desvergne B, et al. Selective cooperation between fatty acid binding proteins and peroxisome proliferator-activated receptors in regulating transcription. Mol Cell Biol 2002; 22:5114-27.

20. Elabdeen HR, Mustafa M, Szklenar M, Rühl R, Ali R, Bolstad Al. Ratio of pro-resolving and pro-inflammatory lipid mediator precursors as potential markers for aggressive periodontitis. PLoS One 2013; 8:e70838.

21. Szklenar M, Kalkowski J, StangI V, Lorenz M, Rühl R. Eicosanoids and docosanoids in plasma and aorta of healthy and atherosclerotic rabbits. J Vasc Res 2013; 50:372-82.

22. Rühl R. Method to determine 4-oxo-retinoic acids, retinoic acids and retinol in serum and cell extracts by liquid chromatography/diode-array detection atmospheric pressure chemical ionisation tandem mass spectrometry. Rapid Commun Mass Spectrom 2006; 20:2497-504.

This article is protected by copyright. All rights reserved. 
23. Agrawal K, Hassoun LA, Foolad N, Pedersen TL, Sivamani RK, Newman JW. Sweat lipid mediator profiling: a noninvasive approach for cutaneous research. J Lipid Res 2017; 58:18895.

24. Ohnishi H, Miyahara N, Gelfand EW. The role of leukotriene $\mathrm{B}(4)$ in allergic diseases. Allergol Int 2008; 57:291-8.

25. Reilly DM, Parslew R, Sharpe GR, Powell S, Green MR. Inflammatory mediators in normal, sensitive and diseased skin types. Acta Derm Venereol 2000; 80:171-4.

26. Fogh K, Kragballe K. Eicosanoids in inflammatory skin diseases. Prostaglandins Other Lipid Mediat 2000; 63:43-54.

27. Blunder S, Ruhl R, Moosbrugger-Martinz V, Krimmel C, Geisler A, Zhu H, et al. Alterations in Epidermal Eicosanoid Metabolism Contribute to Inflammation and Impaired Late Differentiation in FLG-Mutated Atopic Dermatitis. J Invest Dermatol 2017; 137:706-15.

28. Mihaly J, Gamlieli A, Worm M, Rühl R. Decreased retinoid concentration and retinoid signalling pathways in human atopic dermatitis. Exp Dermatol 2011; 20:326-30.

29. Schuster GU, Kenyon NJ, Stephensen CB. Vitamin A deficiency decreases and high dietary vitamin A increases disease severity in the mouse model of asthma. J Immunol 2008; 180:1834-42.

30. Wiedermann U, Chen XJ, Enerback L, Hanson LA, Kahu H, Dahlgren UI. Vitamin A deficiency increases inflammatory responses. Scand J Immunol 1996; 44:578-84.

31. Stephensen CB, Rasooly R, Jiang X, Ceddia MA, Weaver CT, Chandraratna RA, et al. Vitamin A enhances in vitro Th2 development via retinoid $X$ receptor pathway. J Immunol 2002; 168:4495-503.

32. Chapellier B, Mark M, Messaddeq N, Calleja C, Warot X, Brocard J, et al. Physiological and retinoid-induced proliferations of epidermis basal keratinocytes are differently controlled. Embo J 2002; 21:3402-13.

33. Li M, Indra AK, Warot X, Brocard J, Messaddeq N, Kato S, et al. Skin abnormalities generated by temporally controlled RXRalpha mutations in mouse epidermis. Nature 2000; 407:633-6.

This article is protected by copyright. All rights reserved. 
34. Li M, Messaddeq N, Teletin M, Pasquali JL, Metzger D, Chambon P. Retinoid X receptor ablation in adult mouse keratinocytes generates an atopic dermatitis triggered by thymic stromal lymphopoietin. Proc Natl Acad Sci U S A 2005; 102:14795-800.

35. Mihaly J, Gericke J, Aydemir G, Weiss K, Carlsen H, Blomhoff R, et al. Reduced retinoid signaling in the skin after systemic retinoid- $X$ receptor ligand treatment in mice with potential relevance for skin disorders. Dermatology 2013; 225:304-11.

36. Kim N, Luster AD. Regulation of immune cells by eicosanoid receptors. ScientificWorldJournal 2007; 7:1307-28.

37. Kuraishi Y, Ohtsuka E, Nakano T, Kawai S, Andoh T, Nojima H, et al. Possible involvement of 5-lipoxygenase metabolite in itch-associated response of mosquito allergy in mice. J Pharmacol Sci 2007; 105:41-7.

38. Kim DK, Kim HJ, Kim H, Koh JY, Kim KM, Noh MS, et al. Involvement of serotonin receptors 5HT1 and 5-HT2 in 12(S)-HPETE-induced scratching in mice. Eur J Pharmacol 2008; 579:390-4.

39. Andoh T, Nishikawa $Y$, Yamaguchi-Miyamoto T, Nojima H, Narumiya S, Kuraishi $Y$. Thromboxane A2 induces itch-associated responses through TP receptors in the skin in mice. J Invest Dermatol 2007; 127:2042-7.

40. Tsuji F, Aono H, Tsuboi T, Murakami T, Enomoto H, Mizutani K, et al. Role of leukotriene B4 in 5-lipoxygenase metabolite- and allergy-induced itch-associated responses in mice. Biol Pharm Bull 2010; 33:1050-3.

41. Andoh T, Haza S, Saito A, Kuraishi Y. Involvement of leukotriene B4 in spontaneous itchrelated behaviour in NC mice with atopic dermatitis-like skin lesions. Exp Dermatol 2011; 20:894-8.

42. Krieg P, Fürstenberger G. The role of lipoxygenases in epidermis. Biochim Biophys Acta 2014; 1841:390-400.

43. Epp N, Furstenberger G, Muller K, de Juanes S, Leitges M, Hausser I, et al. 12R-lipoxygenase deficiency disrupts epidermal barrier function. J Cell Biol 2007; 177:173-82.

44. Fujii M, Nabe T, Tomozawa J, Kohno S. Involvement of skin barrier dysfunction in itch-related scratching in special diet-fed hairless mice. Eur J Pharmacol 2006; 530:152-6.

This article is protected by copyright. All rights reserved. 
45. Fujii M, Nakashima H, Tomozawa J, Shimazaki Y, Ohyanagi C, Kawaguchi N, et al. Deficiency of $n-6$ polyunsaturated fatty acids is mainly responsible for atopic dermatitis-like pruritic skin inflammation in special diet-fed hairless mice. Exp Dermatol 2013; 22:272-7.

46. Fujii M, Tomozawa J, Mizutani N, Nabe T, Danno K, Kohno S. Atopic dermatitis-like pruritic skin inflammation caused by feeding a special diet to HR-1 hairless mice. Exp Dermatol 2005; 14:460-8.

47. Yen CH, Dai YS, Yang YH, Wang LC, Lee JH, Chiang BL. Linoleic acid metabolite levels and transepidermal water loss in children with atopic dermatitis. Ann Allergy Asthma Immunol 2008; 100:66-73.

48. Schäfer L, Kragballe K. Abnormalities in epidermal lipid metabolism in patients with atopic dermatitis. J Invest Dermatol 1991; 96:10-5.

49. Boguniewicz M, Leung DY. Atopic dermatitis: a disease of altered skin barrier and immune dysregulation. Immunol Rev 2011; 242:233-46.

50. Rühl R, Koch C, Marosvolgyi T, Mihaly J, Schweigert FJ, Worm M, et al. Fatty acid composition of serum lipid classes in mice following allergic sensitisation with or without dietary docosahexaenoic acid-enriched fish oil substitution. Br J Nutr 2008; 99:1239-46.

51. Fogh K, Herlin T, Kragballe K. Eicosanoids in skin of patients with atopic dermatitis: prostaglandin E2 and leukotriene B4 are present in biologically active concentrations. J Allergy Clin Immunol 1989; 83:450-5.

52. Mihaly J, Marosvolgyi T, Szegedi A, Koroskenyi K, Lucas R, Torocsik D, et al. Increased FADS2Derived n-6 PUFAs and Reduced n-3 PUFAs in Plasma of Atopic Dermatitis Patients. Skin Pharmacol Physiol 2014; 27:242-8.

53. Wu SH, Chen XQ, Liu B, Wu HJ, Dong L. Efficacy and safety of $15(\mathrm{R} / \mathrm{S})$-methyl-lipoxin $A(4)$ in topical treatment of infantile eczema. Br J Dermatol 2012; 168:172-8.

54. Marcon R, Bento AF, Dutra RC, Bicca MA, Leite DF, Calixto JB. Maresin 1, a proresolving lipid mediator derived from omega-3 polyunsaturated fatty acids, exerts protective actions in murine models of colitis. J Immunol 2013; 191:4288-98.

55. Andersson CK, Claesson HE, Rydell-Tormanen K, Swedmark S, Hallgren A, Erjefalt JS. Mice lacking 12/15-lipoxygenase have attenuated airway allergic inflammation and remodeling. Am J Respir Cell Mol Biol 2008; 39:648-56.

This article is protected by copyright. All rights reserved. 
56. Hajek AR, Lindley AR, Favoreto S, Jr., Carter R, Schleimer RP, Kuperman DA. 12/15Lipoxygenase deficiency protects mice from allergic airways inflammation and increases secretory IgA levels. J Allergy Clin Immunol 2008; 122:633-9 e3.

57. Yamada T, Tani Y, Nakanishi H, Taguchi R, Arita M, Arai H. Eosinophils promote resolution of acute peritonitis by producing proresolving mediators in mice. Faseb J 2011; 25:561-8.

58. Serhan CN, Jain A, Marleau S, Clish C, Kantarci A, Behbehani B, et al. Reduced inflammation and tissue damage in transgenic rabbits overexpressing 15-lipoxygenase and endogenous anti-inflammatory lipid mediators. J Immunol 2003; 171:6856-65.

59. Setsu N, Matsuura H, Hirakawa S, Arata J, Iwatsuki K. Interferon-gamma-induced 15lipoxygenase-2 expression in normal human epidermal keratinocytes and a pathogenic link to psoriasis vulgaris. Eur J Dermatol 2006; 16:141-5.

60. Huang JT, Welch JS, Ricote M, Binder CJ, Willson TM, Kelly C, et al. Interleukin-4-dependent production of PPAR-gamma ligands in macrophages by 12/15-lipoxygenase. Nature 1999; 400:378-82.

61. Gillbro JM, Al-Bader T, Westman M, Olsson MJ, Mavon A. Transcriptional changes in organoculture of full-thickness human skin following topical application of all-trans retinoic acid. Int J Cosmet Sci 2014; 36:253-61.

62. Gregus AM, Doolen S, Dumlao DS, Buczynski MW, Takasusuki T, Fitzsimmons BL, et al. Spinal 12-lipoxygenase-derived hepoxilin A3 contributes to inflammatory hyperalgesia via activation of TRPV1 and TRPA1 receptors. Proc Natl Acad Sci U S A 2012; 109:6721-6.

63. Kim DK, Kim HJ, Sung KS, Kim H, Cho SA, Kim KM, et al. 12(S)-HPETE induces itch-associated scratchings in mice. Eur J Pharmacol 2007; 554:30-3.

64. Westergaard M, Henningsen J, Svendsen ML, Johansen C, Jensen UB, Schroder HD, et al. Modulation of keratinocyte gene expression and differentiation by PPAR-selective ligands and tetradecylthioacetic acid. J Invest Dermatol 2001; 116:702-12.

65. Gericke J, Ittensohn J, Mihaly J, Alvarez S, Alvarez R, Töröcsik D, et al. Regulation of retinoidmediated signaling involved in skin homeostasis by RAR and RXR agonists/antagonists in mouse skin. PLoS ONE 2013; 8:e62643.

This article is protected by copyright. All rights reserved. 
66. Romanowska M, al Yacoub N, Seidel H, Donandt S, Gerken H, Phillip S, et al. PPARdelta enhances keratinocyte proliferation in psoriasis and induces heparin-binding EGF-like growth factor. J Invest Dermatol 2008; 128:110-24.

67. Romanowska M, Reilly L, Palmer CN, Gustafsson MC, Foerster J. Activation of PPARbeta/delta causes a psoriasis-like skin disease in vivo. PLoS One 2010; 5:e9701.

68. Munoz-Garcia A, Thomas CP, Keeney DS, Zheng Y, Brash AR. The importance of the lipoxygenase-hepoxilin pathway in the mammalian epidermal barrier. Biochim Biophys Acta 2014; 1841:401-8.

69. Satoh T, Moroi R, Aritake K, Urade Y, Kanai Y, Sumi K, et al. Prostaglandin D2 plays an essential role in chronic allergic inflammation of the skin via CRTH2 receptor. J Immunol 2006; 177:2621-9.

70. Spik I, Brenuchon C, Angeli V, Staumont D, Fleury S, Capron M, et al. Activation of the prostaglandin D2 receptor DP2/CRTH2 increases allergic inflammation in mouse. J Immunol $2005 ; 174: 3703-8$.

71. He R, Oyoshi MK, Wang JY, Hodge MR, Jin H, Geha RS. The prostaglandin D(2) receptor CRTH2 is important for allergic skin inflammation after epicutaneous antigen challenge. J Allergy Clin Immunol 2010; 126:784-90.

72. Murata T, Aritake K, Tsubosaka Y, Maruyama T, Nakagawa T, Hori M, et al. Antiinflammatory role of PGD2 in acute lung inflammation and therapeutic application of its signal enhancement. Proc Natl Acad Sci U S A 2013; 110:5205-10.

73. Honma Y, Arai I, Hashimoto Y, Futaki N, Sugimoto M, Tanaka M, et al. Prostaglandin D2 and prostaglandin E2 accelerate the recovery of cutaneous barrier disruption induced by mechanical scratching in mice. Eur J Pharmacol 2005; 518:56-62.

74. Takaoka A, Arai I, Sugimoto M, Futaki N, Sakurai T, Honma Y, et al. Role of scratch-induced cutaneous prostaglandin $\mathrm{D}$ production on atopic-like scratching behaviour in mice. Exp Dermatol 2007; 16:331-9.

75. Kostenis E, Ulven T. Emerging roles of DP and CRTH2 in allergic inflammation. Trends Mol Med 2006; 12:148-58.

76. Kliewer SA, Sundseth SS, Jones SA, Brown PJ, Wisely GB, Koble CS, et al. Fatty acids and eicosanoids regulate gene expression through direct interactions with peroxisome

This article is protected by copyright. All rights reserved. 
proliferator-activated receptors alpha and gamma. Proc Natl Acad Sci U S A 1997; 94:431823.

77. Schmuth M, Watson RE, Deplewski D, Dubrac S, Zouboulis CC, Griffiths CE. Nuclear hormone receptors in human skin. Horm Metab Res 2007; 39:96-105.

78. Dubrac S, Schmuth M. PPAR-alpha in cutaneous inflammation. Dermatoendocrinol 2011; 3:23-6.

79. Shiraki T, Kamiya N, Shiki S, Kodama TS, Kakizuka A, Jingami H. Alpha, beta-unsaturated ketone is a core moiety of natural ligands for covalent binding to peroxisome proliferatoractivated receptor gamma. J Biol Chem 2005; 280:14145-53.

80. Itoh T, Fairall L, Amin K, Inaba Y, Szanto A, Balint BL, et al. Structural basis for the activation of PPARgamma by oxidized fatty acids. Nat Struct Mol Biol 2008; 15:924-31.

81. Koch C, Dolle S, Metzger M, Rasche C, Jungclas H, Rühl R, et al. Docosahexaenoic acid (DHA) supplementation in atopic eczema: a randomized, double-blind, controlled trial. $\mathrm{Br} \mathrm{J}$ Dermatol 2008; 158:786-92.

This article is protected by copyright. All rights reserved. 


\section{Tables:}

Table 1:

$$
\text { H-SE (conc. in } \mathrm{ng} / \mathrm{ml} \text { ) D-SE (conc. in } \mathrm{ng} / \mathrm{ml} \text { ) Significance }
$$

\begin{tabular}{|c|c|c|c|c|c|}
\hline AA & 314.8 & \pm 74.8 & 265.6 & \pm 168.4 & 0.67 \\
\hline 5-HETE & 6.1 & \pm 5.8 & 0.5 & \pm 0.5 & 0.17 \\
\hline 8-HETE* & 0.7 & \pm 0.3 & 0.4 & \pm 0.5 & 0.51 \\
\hline 11-HETE & 1.0 & \pm 0.3 & 1.0 & \pm 0.8 & 1.00 \\
\hline 12-HETE & 42.5 & \pm 11.1 & 99.6 & \pm 92.2 & 0.35 \\
\hline 15-HETE & 1.6 & \pm 0.4 & 2.4 & \pm 2.1 & 0.57 \\
\hline 20-HETE & 0.8 & \pm 0.4 & 2.1 & \pm 2.0 & 0.33 \\
\hline LTB4* & 3.3 & \pm 3.9 & 0.5 & \pm 0.6 & 0.29 \\
\hline 20-OH-LTB4* & 0.1 & $\pm<0.1$ & 0.2 & \pm 0.3 & 0.43 \\
\hline 20-COOH-LTB4 & 0.9 & \pm 0.7 & 0.5 & $\pm<0.1$ & 0.37 \\
\hline 20-СOOH-AA & 0.8 & \pm 0.5 & 2.6 & \pm 2.6 & 0.29 \\
\hline LTC4* & 0.3 & \pm 0.2 & 0.2 & \pm 0.2 & 0.48 \\
\hline PGD2 & 4.7 & \pm 2.2 & 6.8 & \pm 2.9 & 0.37 \\
\hline PGE2 & 6.8 & \pm 0.8 & 6.2 & \pm 3.5 & 0.77 \\
\hline d15d12PGD2* & 1.1 & \pm 0.3 & 0.6 & \pm 0.6 & 0.25 \\
\hline PGJ2* & 0.3 & \pm 0.5 & 0.4 & \pm 0.2 & 0.76 \\
\hline d15d12PGJ2* & $<0.1$ & $\pm<0.1$ & 0.1 & $\pm<0.1$ & 0.38 \\
\hline TXB2 & 31.2 & \pm 10.7 & 52.5 & \pm 52.1 & 0.53 \\
\hline 8i-PGF2a & 2.1 & \pm 2.4 & 2.6 & \pm 2.5 & 0.81 \\
\hline PGF2a & 0.8 & \pm 0.2 & 0.9 & \pm 0.7 & 0.75 \\
\hline 5-KETE & 0.7 & \pm 0.5 & 1.0 & \pm 0.8 & 0.65 \\
\hline 12-KETE* & 1.1 & \pm 1.9 & 3.3 & \pm 2.4 & 0.28 \\
\hline 15-KETE* & 2.4 & \pm 2.1 & 0.1 & $\pm<0.1$ & 0.13 \\
\hline LXB4* & 0.1 & $\pm<0.1$ & 0.2 & \pm 0.1 & 0.40 \\
\hline LXA4* & 0.4 & \pm 0.1 & 0.1 & $\pm<0.1$ & $<0.01$ \\
\hline HXA3* & 2.1 & \pm 2.2 & 1.4 & \pm 0.8 & 0.64 \\
\hline HXB3* & 0.6 & \pm 0.5 & 1.0 & \pm 1.6 & 0.74 \\
\hline
\end{tabular}

This article is protected by copyright. All rights reserved. 


\begin{tabular}{|c|c|c|c|c|c|}
\hline EPA & 81.7 & \pm 39.6 & 38.8 & \pm 35.8 & 0.24 \\
\hline 5-HEPE* & 3.0 & \pm 2.6 & 0.1 & \pm 0.1 & 0.13 \\
\hline 8-HEPE & 1.0 & \pm 0.4 & 1.1 & \pm 1.4 & 0.89 \\
\hline 12-HEPE & 2.8 & \pm 1.7 & 3.8 & \pm 4.7 & 0.74 \\
\hline 15-HEPE* & 0.4 & \pm 0.2 & 0.4 & \pm 0.3 & 0.75 \\
\hline 18-HEPE* & 0.3 & \pm 0.5 & 1.4 & \pm 1.7 & 0.37 \\
\hline LTB5* & 0.5 & \pm 0.3 & 0.1 & \pm 0.1 & 0.05 \\
\hline PGE3 & 0.8 & \pm 0.4 & 3.6 & \pm 3.0 & 0.18 \\
\hline DHA & 205.2 & \pm 79.9 & 70.4 & \pm 30.0 & 0.03 \\
\hline 4-HDHA* & 5.8 & \pm 5.1 & 0.1 & \pm 0.1 & 0.12 \\
\hline 10-HDHA* & 0.6 & \pm 0.4 & 0.3 & \pm 0.1 & 0.29 \\
\hline 14-HDHA & 2.9 & \pm 1.9 & 1.8 & \pm 2.1 & 0.53 \\
\hline 17-HDHA* & 1.2 & \pm 0.9 & 0.4 & \pm 0.5 & 0.27 \\
\hline 20-HDHA & 0.6 & \pm 0.4 & 0.5 & \pm 0.2 & 0.66 \\
\hline RvD1* & 0.4 & \pm 0.5 & 0.1 & $\pm<0.1$ & 0.31 \\
\hline RvD2 & 2.2 & \pm 2.1 & 0.4 & $\pm<0.1$ & 0.20 \\
\hline MAR* & 0.4 & \pm 0.1 & 0.1 & $\pm<0.1$ & $<0.01$ \\
\hline PD1* & 0.3 & \pm 0.2 & 0.1 & \pm 0.1 & 0.12 \\
\hline LA & 365.2 & \pm 89.5 & 194.2 & \pm 173.4 & 0.43 \\
\hline 9-HODE & 4.3 & \pm 1.6 & 4.6 & \pm 0.5 & 0.78 \\
\hline 13-HODE & 5.1 & \pm 1.1 & 6.9 & \pm 0.9 & 0.04 \\
\hline 13-KODE & 19.2 & \pm 7.5 & 14.7 & \pm 5.5 & 0.45 \\
\hline
\end{tabular}

The concentration of lipid mediators in serum samples from healthy volunteers (H-SE) $(n=3)$ and patients with AD (D-SE) ( $\mathrm{n}=3)$ were measured by HPLC-MS-MS. Results in $\mathrm{ng} / \mathrm{ml}$ are expressed as mean \pm SD. Numbers in bold letters are significantly different $(P<0.05$, Mann Whitney test) and numbers in italic letters just identify a tendency of significance $(p<0.1)$. Abbreviations see legend to figure $1 .{ }^{*}$ For the marked substances values which were under the quantification limit of the used methodology of $0.2 \mathrm{ng} / \mathrm{ml}$ were replaced with a value of half of the detection limit $(0.1 \mathrm{ng} / \mathrm{ml})$.

This article is protected by copyright. All rights reserved. 
Table 2:

$\begin{array}{llll}\text { H-SK N-SK } & \text { A-SK } & \text { Significance }\end{array}$

conc. in $\mathrm{ng} / \mathrm{g} \quad$ conc. in $\mathrm{ng} / \mathrm{g} \quad$ conc. in $\mathrm{ng} / \mathrm{g}$

$\mathrm{H}: \mathrm{N} \quad \mathrm{H}: \mathrm{A}$

$\mathrm{N}: \mathrm{A}$

AA

$772.5 \quad \pm 83.0 \quad 1563.2 \pm 353.41408 .0 \pm 427.2$

0.02

0.05

0.65

5-HETE

$\begin{array}{llllll}0.3 & \pm 0.1 & 0.8 & \pm 0.4 & 1.2 & \mathbf{0}\end{array}$

0.08

$<0.01$

0.10

8-HETE

$\begin{array}{llllll}0.7 & \pm 0.3 & 1.3 & \pm 0.4 & 6.2 & \pm 4.5\end{array}$

0.11

0.10

0.13

11-HETE

$\begin{array}{llllll}0.8 & \pm 0.2 & 1.9 & \pm 0.8 & \mathbf{2 . 1} & \mathbf{0} .7\end{array}$

0.07

0.03

0.79

12-HETE

$\begin{array}{llllll}35.0 & \pm 33.3 & 88.1 & \pm 60.8 & 70.1 & \pm 39.2\end{array}$

0.26

0.30

0.69

15-HETE

$\begin{array}{llllll}5.5 & \pm 3.7 & 9.5 & \pm 3.2 & 118.3 \quad \pm 143.3\end{array}$

0.23

0.24

0.26

20-HETE*

$\begin{array}{llllll}2.1 & \pm 0.8 & 7.2 & \pm 7.3 & 2.6 & \pm 2.5\end{array}$

0.29

0.77

0.35

LTB4*

$\begin{array}{llllll}0.1 & \pm 0.1 & 0.5 & \pm 0.3 & \mathbf{1 . 4} & \mathbf{0}\end{array}$

0.10

0.01

0.04

$\begin{array}{lllllll}\text { 20-OH-LTB4 } * & 0.2 & \pm 0.1 & 1.0 & \pm 1.4 & 1.9 & \pm 1.7\end{array}$

0.39

0.15

0.49

$\begin{array}{lllllll}\text { 20-COOH-LTB4 } & 7.2 & \pm 8.0 & 12.1 & \pm 10.0 & 5.9 & \pm 4.1\end{array}$

0.54

0.82

0.38

$\begin{array}{lllllll}\text { 20-COOH-AA* }^{*} & 5.1 & \pm 5.9 & 2.4 & \pm 2.2 & 1.4 & \pm 2.0\end{array}$

0.50

0.36

0.57

LTC4

$\begin{array}{llllll}0.9 & \pm 0.2 & 0.5 & \pm 0.2 & 0.5 & \pm 0.5\end{array}$

0.07

0.36

0.97

PGD2

$27.1 \quad \pm 14.7 \quad 104.5 \quad \pm 102.0 \quad 62.3 \quad \pm 40.1$

0.26

0.23

0.54

PGE2

$\begin{array}{llllll}36.8 & \pm 19.6 & 143.8 & \pm 66.1 & 66.1 & \pm 12.5\end{array}$

0.05

0.04

0.12

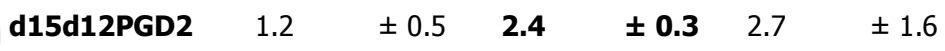

0.01

0.18

0.74

PGJ2*

$\begin{array}{llllll}0.1 & \pm 0.2 & 2.9 & \pm 1.9 & \mathbf{2 . 1} & \mathbf{0}\end{array}$

0.07

$<0.01$

0.51

$\begin{array}{lllllll}\text { d15d12PGJ2* } & 0.1 & \pm 0.1 & 0.2 & \pm 0.2 & 0.1 & \pm 0.1\end{array}$

0.33

0.61

0.23

TXB2*

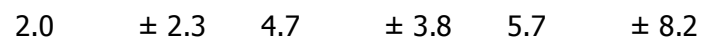

0.35

0.49

0.85

8i-PGF2a*

$3.7 \pm 3$

$11.3 \quad \pm 4.9 \quad 6.9 \quad \pm 3.2$

0.09

0.29

0.27

PGF2a

$3.3 \pm 2$

$23.3 \quad \pm 13.0 \quad 8.6 \quad \pm 2.2$

0.03

0.02

0.12

5-KETE*

$\begin{array}{llllll}1.5 & \pm 1.4 & 0.5 & \pm 0.8 & 0.8 & \pm 0.7\end{array}$

0.32

0.45

0.64

12-KETE*

$\begin{array}{llllll}4.7 & \pm 2.6 & 6.2 & \pm 6.0 & 10.5 & \pm 9.4\end{array}$

0.71

0.36

0.54

15-KETE*

$\begin{array}{llllll}1.4 & \pm 1.2 \quad 4.8 & \pm 4.2 & 25.8 & \pm 16.6\end{array}$

0.24

0.06

0.10

LXB4*

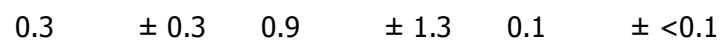

0.45

0.38

0.34

LXA4*

$\begin{array}{llllll}0.3 & \pm 0.1 & 0.5 & \pm 0.5 & 0.7 & \pm 0.5\end{array}$

0.49

0.23

0.68

HXA3

$\begin{array}{llllll}2.0 & \pm 1.9 & 11.2 & \pm 9.5 & 9.1 & \pm 9.4\end{array}$

0.18

0.27

0.80

HXB3

$\begin{array}{llllll}3.2 & \pm 4.3 & 5.6 & \pm 4.0 & 10.5 & \pm 8.3\end{array}$

0.50

0.25

0.42

EPA 


\begin{tabular}{|c|c|c|c|c|c|c|c|c|c|}
\hline 5-HEPE* & 0.1 & \pm 0.1 & 0.1 & $\pm<0.1$ & 0.3 & \pm 0.2 & 0.20 & 0.12 & 0.18 \\
\hline 8-HEPE* & 1.9 & \pm 1.3 & 1.8 & \pm 2.4 & 5.1 & \pm 4.3 & 0.96 & 0.28 & 0.31 \\
\hline 12-HEPE & 5.9 & \pm 4.5 & 9.4 & \pm 6.9 & 5.8 & \pm 0.6 & 0.50 & 0.96 & 0.41 \\
\hline 15-HEPE & 2.0 & \pm 1.2 & 2.4 & \pm 1.0 & 10.0 & \pm 7.1 & 0.64 & 0.13 & 0.14 \\
\hline 18-HEPE* & 5.5 & \pm 5.0 & 2.4 & \pm 1.0 & 2.7 & \pm 4.5 & 0.36 & 0.51 & 0.93 \\
\hline LTB5* & 0.2 & \pm 0.4 & 0.4 & \pm 0.6 & 0.7 & \pm 0.6 & 0.77 & 0.33 & 0.53 \\
\hline PGE3 & 6.5 & \pm 9.8 & 2.3 & \pm 1.8 & 16.5 & \pm 15.4 & 0.51 & 0.40 & 0.19 \\
\hline DHA & 141.7 & \pm 37.3 & 114.7 & \pm 29.5 & 153.7 & \pm 46.0 & 0.38 & 0.74 & 0.28 \\
\hline 4-HDHA* & 0.1 & \pm 0.1 & 0.2 & \pm 0.2 & 0.4 & \pm 0.1 & 0.57 & $<0.01$ & 0.11 \\
\hline 10-HDHA* & 0.2 & $\pm<0.1$ & 0.5 & \pm 0.2 & 1.1 & \pm 0.6 & 0.14 & 0.03 & 0.13 \\
\hline 14-HDHA & 4.2 & \pm 2.8 & 8.3 & \pm 7.5 & 9.4 & \pm 6.7 & 0.43 & 0.28 & 0.86 \\
\hline 17-HDHA & 2.1 & \pm 1.3 & 3.4 & \pm 0.8 & 33.9 & \pm 27.1 & 0.24 & 0.11 & 0.12 \\
\hline 20-HDHA* & 0.4 & \pm 0.3 & 0.3 & \pm 0.3 & 0.7 & \pm 0.6 & 0.92 & 0.39 & 0.34 \\
\hline RvD1* & 0.5 & \pm 0.5 & 2.7 & \pm 3.4 & 0.2 & \pm 0.1 & 0.34 & 0.37 & 0.29 \\
\hline RvD2 & 3.8 & \pm 5.0 & 5.1 & \pm 4.0 & 1.5 & \pm 0.5 & 0.74 & 0.48 & 0.20 \\
\hline MAR* & 0.4 & \pm 0.4 & 0.4 & \pm 0.2 & 0.3 & \pm 0.3 & 0.99 & 0.93 & 0.90 \\
\hline PD1* & 0.3 & \pm 0.5 & 0.3 & \pm 0.2 & 0.7 & \pm 0.2 & 0.81 & 0.29 & 0.04 \\
\hline LA & 247.9 & \pm 36.4 & 430.7 & \pm 179.9 & 311.4 & \pm 46.0 & 0.16 & 0.13 & 0.33 \\
\hline 9-HODE & 31.2 & \pm 9.6 & 91.9 & \pm 72.0 & 59.7 & \pm 37.3 & 0.22 & 0.27 & 0.53 \\
\hline 13-HODE & 54.0 & \pm 19.6 & 83.6 & \pm 23.1 & 211.0 & \pm 135.9 & 0.17 & 0.12 & 0.18 \\
\hline 13-KODE & 146.4 & \pm 43.3 & 110.6 & \pm 64.3 & 377.7 & \pm 190.0 & 0.47 & 0.11 & 0.08 \\
\hline
\end{tabular}

The concentration of lipid mediators in skin samples from healthy volunteers (H-SK) $(n=3)$, non-affected skin samples (N-SK) $(n=3)$ and affected skin samples from patients with AD (A-SK) $(n=3)$ were measured by HPLC-MS-MS. Results in $\mathrm{ng} / \mathrm{ml}$ are expressed as mean \pm SD. Numbers in bold letters are significantly different $(P<0.05$, Mann Whitney test) and numbers in italic letters just identify a tendency of significance $(p<0.1) . *$ For the marked substances selected values which were under the quantification limit of the used methodology of $0.2 \mathrm{ng} / \mathrm{g}$ were replaced with a value of half of the detection limit $(0.1$ $\mathrm{ng} / \mathrm{g})$.

This article is protected by copyright. All rights reserved. 


\section{Figure legends:}

Figure 1: Schematic diagram of derivatives which were mainly determined using our HPLC MS-MS competence. Derivatives which are more than $20 \%$ upregulated in serum of patients with $A D$ in comparison to healthy controls are marked with red and derivatives which are more than $20 \%$ downregulated are marked with blue. Abbreviations: ALA - alpha-linolenic acid, EPA - eicosapentaenoic acid, DPA docosapentaenoic acid, DHA - docosahexaenoic acid, LA - linoleic acid, GLA gamma-linolenic acid, DHGLA - dihydro-gamma-linolenic acid, AA - arachidonic acid, 5-HEPE - 5-hydroxy-eicosapentaenoic acid, 8-HEPE - 8-hydroxy-eicosapentaenoic acid, 12-HEPE - 12-hydroxy-eicosapentaenoic acid, 15-HEPE - 15-hydroxyeicosapentaenoic acid, 18-HEPE - 18-hydroxy-eicosapentaenoic acid, LTB5 leukotriene B5, 4-HDHA - 4-hydroxy-docosahexaenoic acid, 10-HDHA - 10-hydroxydocosahexaenoic acid, 14-HDHA - 14-hydroxy-docosahexaenoic acid, 17-HDHA - 17hydroxy-docosahexaenoic acid, 20-HDHA - 20-hydroxy-docosahexaenoic acid, PD1 protectin D1, RvD1 - resolvin D1, RvD2 - resolvin D2, 9-HODE - 9-hydroxy-10,12octadecadienoic acid, 13-HODE - 13-hydroxy-9,11-octadecadienoic acid, 13-KODE 13-oxo-9,11-octadecadienoic acid, 5-HETE - 5-hydroxy-eicosatetraenoic acid, 8-HETE - 8-hydroxy-eicosatetraenoic acid, 11-HETE - 11-hydroxy-eicosatetraenoic acid, 12HETE - 12-hydroxy-eicosatetraenoic acid, 15-HETE - 15-hydroxy-eicosatetraenoic acid, 20-HETE - 20-hydroxy-eicosatetraenoic acid, LTB4 - leukotriene B4, 20-OHLTB4 - 20-hydroxy-leukotriene B4, 20-COOH-LTB4 - 20-carbohydroxy-leukotriene B4, 20-COOH-AA - 20-carbohydroxy- arachidonic acid, LTC4 - leukotriene C4, PGH2 prostaglandin H2, PGD2 - prostaglandin D2, PGE2 - prostaglandin E2, PGF2a prostaglandin F2a, PGJ2 - prostaglandin J2, PGE3 - prostaglandin E3, d15d12PGJ215-deoxy- $\Delta 12,14$-prostaglandin 32 , d15d12PGD2 - 15-deoxy- $\Delta 12,14$-prostaglandin D2, TXB2 - thromboxane B2, 8i-PGF2a - 8-iso-prostaglandin F2a, 5-KETE - 5-oxoeicosatetraenoic acid, 12-KETE - 12-oxo-eicosatetraenoic acid, 15-KETE - 15-oxoeicosatetraenoic acid, LXB4 - lipoxin B4, LXA4 - lipoxin A4, HXA3 - hepoxilin A3, HXB3 - hepoxilin B3, MAR - maresin. 
Figure 2: (A) Calculated sums and ratios of various eicosanoids, docosanoids and PUFAs $(A A, E P A, D H A, L A)$. Sums are calculated from metabolites originating from AA, EPA, DHA, LA and from 5-LOX, 12-LOX, 15-LOX, COX and 8-hydroxylation (8-OH) pathways as well as summarized HETEs, HEPEs, HDHAs, HODEs. Ratios were calculated from PUFAs, HETEs, HEPEs, HDHAs, HODEs, summarised PUFA-metabolites as well as pro-inflammatory (LTB4, LTC4, PGD2, PGE2, PGF2, d15d12PGD2, TXB2 and 5-KETE) and pro-resolving (LXA4, LXB4, RvD1, RvD2, PD1, MAR) lipid mediators (pro-inf / pro-res) originating from AA, EPA, DHA and LA in affected (A-SK), non-affected skin (N-SK) of AD-patients compared to skin of healthy controls (H-SK) as well as serum of AD-patients (D-SE) in comparison to serum from healthy volunteers (H-SE). (B) The calculated amounts of AA-, DHA-, EPA- and LA-derived PUFA-metabolites were displayed as percentile amounts for affected (A-SK), non-affected skin (N-SK) of AD-patients compared to skin of healthy controls (H-SK). (C) Sum of itchmediators (12-HETE, LTB4, TXB2, PGE2, PGF2) in skin biopsies from affected (A-SK), nonaffected skin (N-SK) of AD-patients compared to skin of healthy controls (H-SK). (D) Ratio of summarised 12LOX / 15LOX metabolites like listed in table 1 and 2 and (E) calulated sums of PPAR-ligands (d15d12PGJ2, 12-KETE, 15-KETE, 13-KODE, PGD2, PGJ2 and 4-HDHA) in affected (A-SK), non-affected skin (N-SK) of AD-patients compared to skin of healthy controls (H-SK). Abbreviations: 5-LOX - 5-lipoxygenase, 8-OH - 8-hydroxylation pathway, 12-LOX - 12-lipoxygenase, 15-LOX - 15-lipoxygenase, COX - cyclooxygenase. Other listed abbreviations see legend of figure 1 .

Figure 3: Calculated upregulation and downregulation of the normalized mRNA expression levels of various enzymes and receptors clustered and calculated for different functional metabolic pathways (5-LOX, 12/15-LOX, COX pathways, PPAR receptors and PPAR-target genes and fatty acid binding proteins) involved in PUFA-metabolite signaling in affected (ASK) $(n=6)$ and non-affected skin $(N-S K)(n=6)$ of AD-patients in comparison to healthy controls $(H-S K)(n=6)$.

This article is protected by copyright. All rights reserved. 
Figure 4: Expression of COX1 and ALOX12B in the skin from healthy controls and patients with atopic dermatitis. Representative immunohistochemical images of COX1 and ALOX12B staining in healthy (H-SK), non affected skin of AD-patients (N-SK) and affected skin of ADpatients (A-SK). Strong presence of ALOX12B and COX1 proteins in epidermis is marked by black arrows, while strong presence of both proteins in the dermal infiltrating cells are marked by the green arrow. Bars, $100 \mu \mathrm{m}$.

This article is protected by copyright. All rights reserved. 


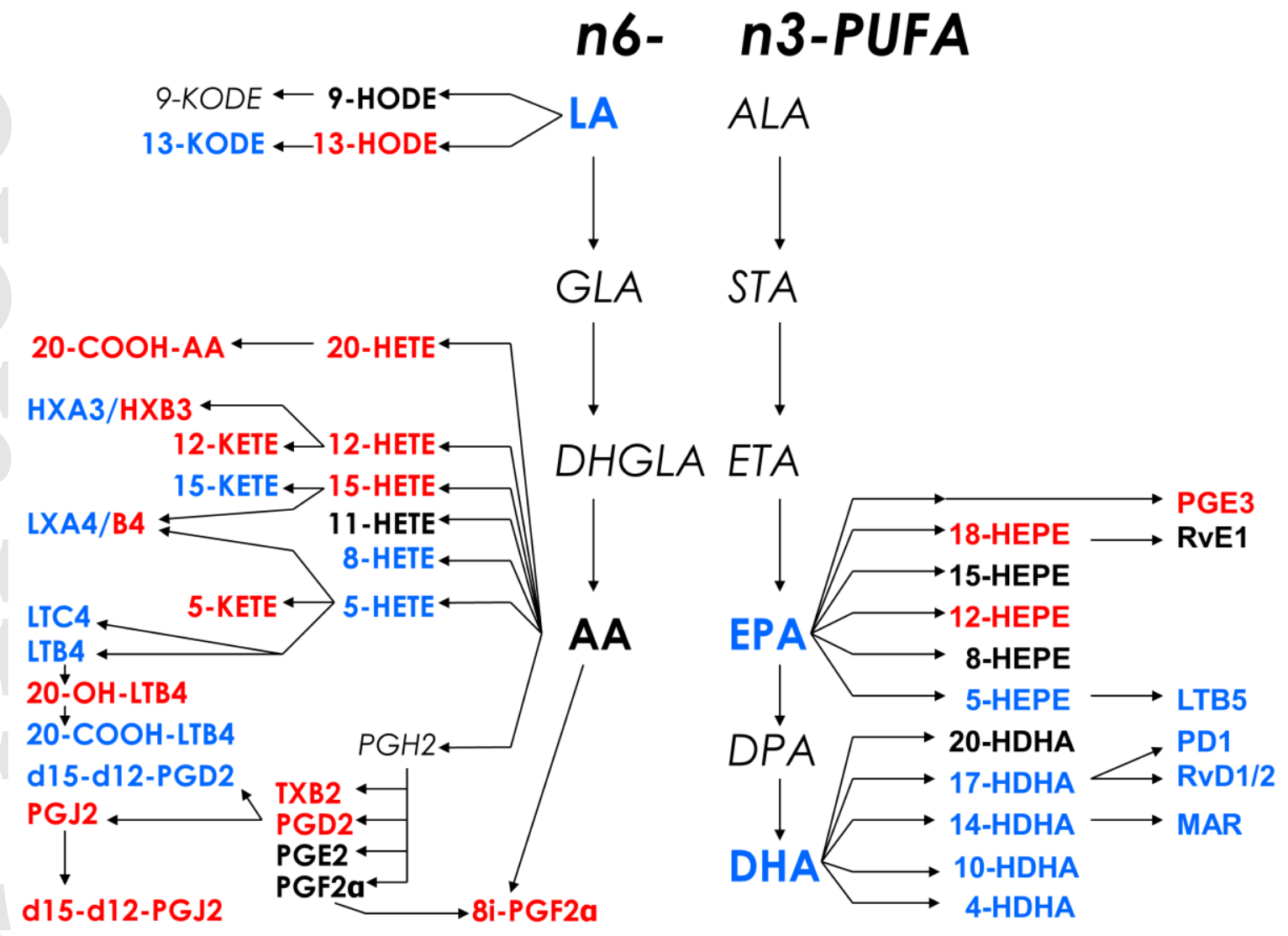

This article is protected by copyright. All rights reserved. 


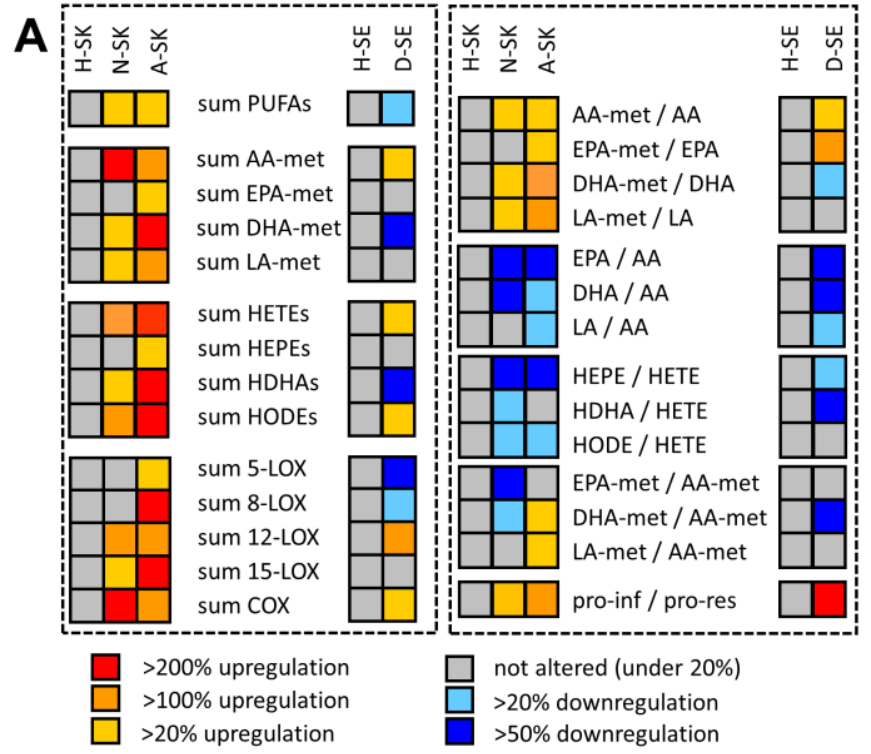

B

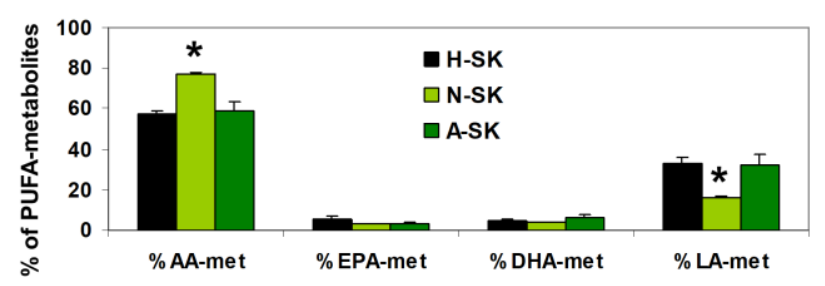

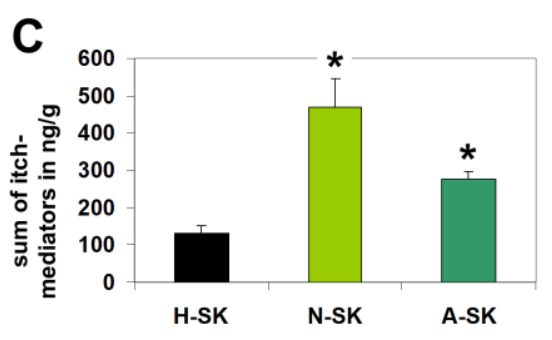

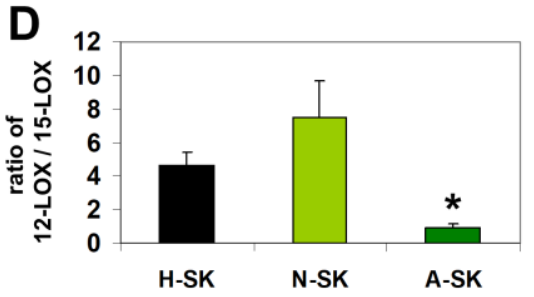

E

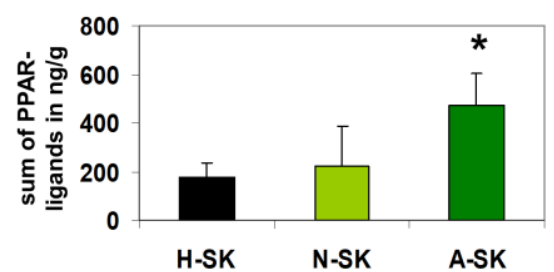

This article is protected by copyright. All rights reserved. 


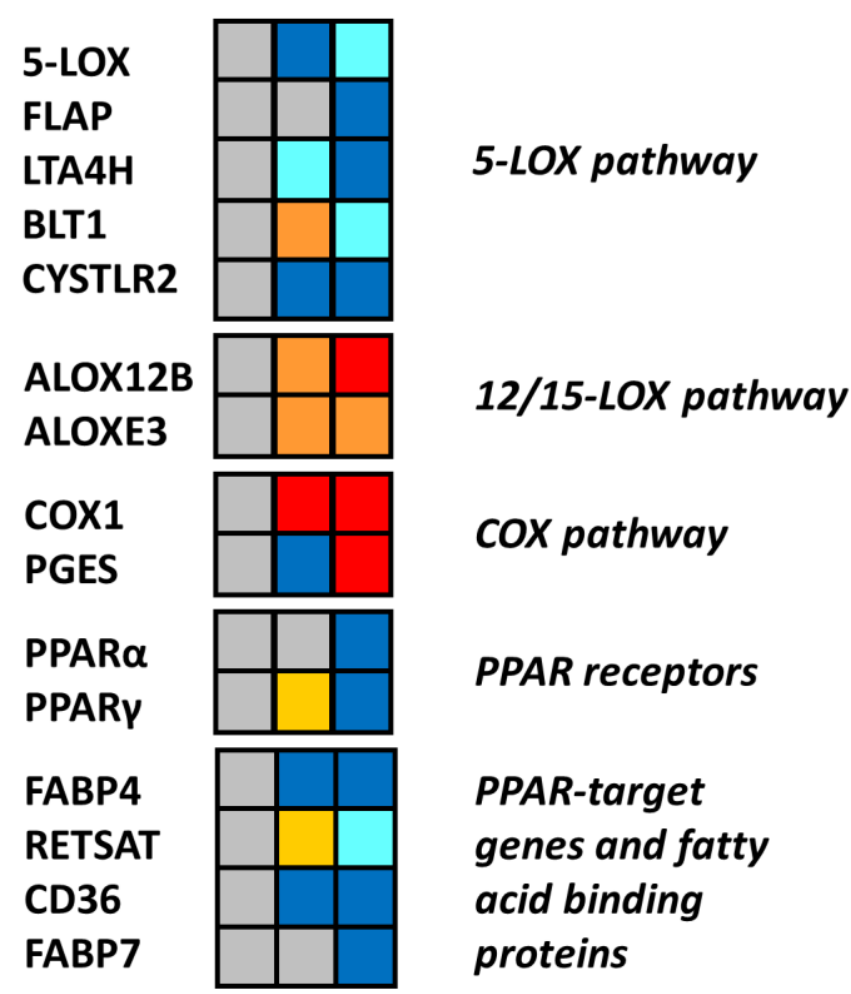

\begin{tabular}{|c|c|}
\hline$>200 \%$ upregulation & not altered (under $\mathbf{2 0 \%}$ \\
\hline$>100 \%$ upregulation & $>20 \%$ downregulation \\
\hline$>20 \%$ upregulation & $>50 \%$ downregulation \\
\hline
\end{tabular}




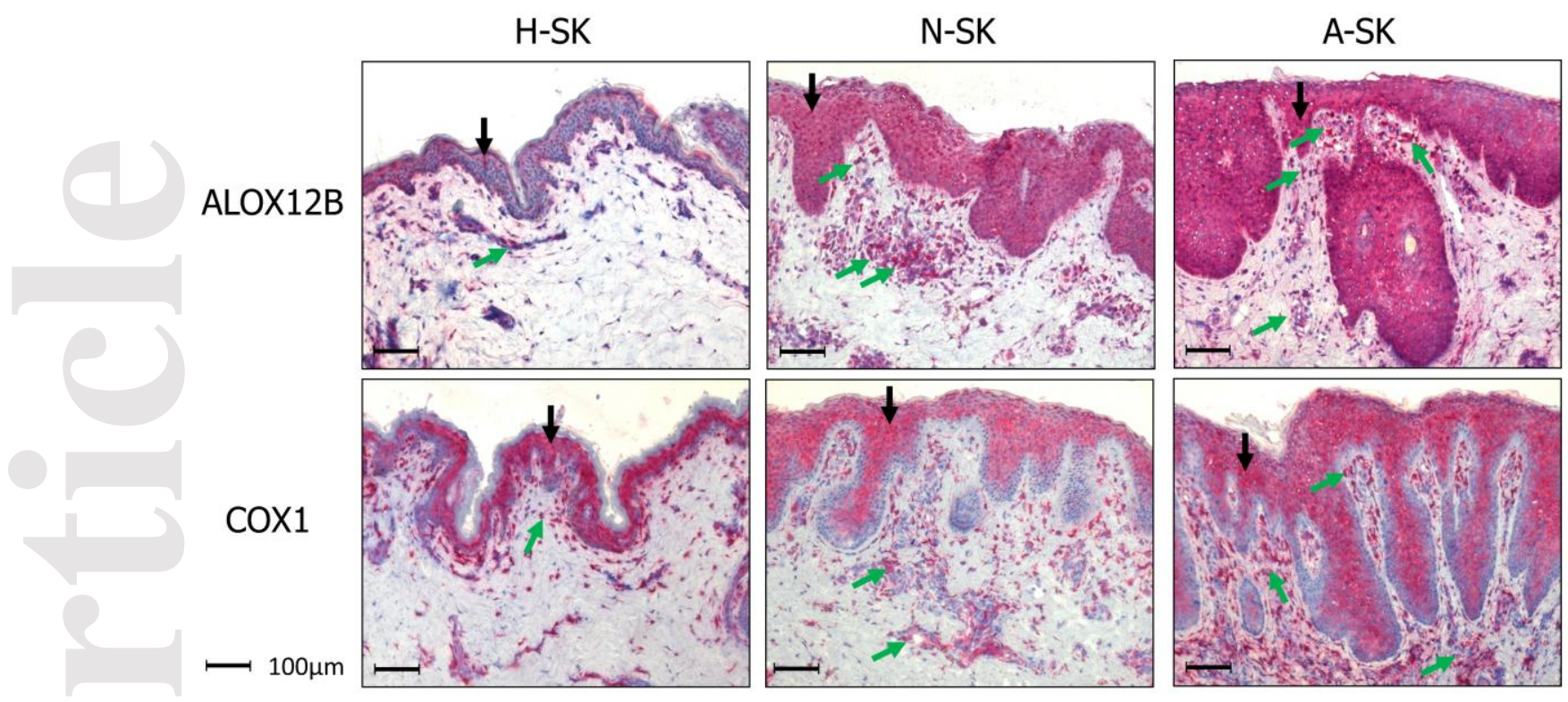

This article is protected by copyright. All rights reserved. 